\title{
Effect of prior differential taste experience on retention of taste quality
}

\author{
CHARLES F. FLAHERTY and BRUCE R. LOMBARDI \\ Rutgers University, New Brunswick, New Jersey 08903
}

\begin{abstract}
In Phase 1 three groups of rats had access to both $32 \%$ and $4 \%$, only $32 \%$, or only $4 \%$ sucrose solutions. In Phase 2 the first group received only $32 \%$, the other groups remained as before; in Phase 3 all groups were shifted to $4 \%$ after a 1- or 10-day interval. In Phase 1 Group 32-4 showed both positive and negative contrast. In Phase 3 successive negative contrast occurred in both retention intervals, but was smaller after the 10-day interval. Following the 10-day interval (but not the 1-day interval), the group with differential experience in Phase 1 (Group 32-4) showed larger contrast than did Group 32-32. Results are discussed in terms of factors determining generalization and memory.
\end{abstract}

The performance of rats shifted from a large to a small reward is typically inferior to rats that have experienced only a small reward. This difference in performance, termed a negative contrast effect, has been found with shifts in amount of solid food reward and with shifts in the concentration of sucrose solutions.

With both types of reward shift, degree of contrast varies as a function of the time between the last experience with the preshift reward and the first experience with the postshift reward (e.g., Flaherty, Capobianco, \& Hamilton, 1973; Gleitman \& Steinman, 1964; Gonzalez, Fernhoff, \& David, 1973; Gordon, Flaherty, \& Riley, 1973). In these studies reliable negative contrast effects have been found in runway behavior following a shift in number of food pellets with 1- and 26-day retention intervals inserted between shift phases, but not with 68-day or 42-day retention intervals (Gonzalez et al., 1973). With shifts from a $32 \%$ sucrose solution to a $4 \%$ sucrose solution, contrast effects in consummatory behavior have been obtained with 1-, 4-, and 5-day retention intervals, and marginally with a 17-day interval, but not with a 32-day retention interval (Ciszewski \& Flaherty, in press; Flaherty et al., 1973; Gordon et al., 1973).

In this paper we are concerned with a possible interpretation of the forgetting of taste quality, as measured by sucrose contrast experiments, and with a treatment that may influence this forgetting. It seems reasonable to assume that each concentration of sucrose represents a point on a stimulus continuum and that there is generalization between these points. Data obtained from instrumental learning experiments varying brightness cues have indicated that generalization gradients tend to broaden as a function of the length of the interval

This research was supported by a Biological Sciences support grant and by a grant from the Rutgers Research Council, both to the first author. Reprint requests should be addressed to Charles F. Flaherty, Psychology Department, Busch Campus, Rutgers University, New Brunswick, New Jersey 08903. inserted between training and testing (Perkins \& Weyant, 1958; Steinman, 1967). If the same process takes place with the aftereffects of sucrose taste, then the failure of contrast to occur after the passage of time might be due to the lack of a discriminable difference between the postshift solution and the memory of the preshift solution because of the generalization between the two. Conceptualizing the problem in these terms allows an experimental attack on the retention of contrast in terms of treatments that might influence stimulus discriminability. For example, it is well established that, in operant studies, prior discrimination training reduces generalization (e.g., Hanson, 1959). A similar effect of prior differential experience on later generalization is expected from a perceptual learning point of view (Gibson, 1963, p. 40; James, 1890, pp. 508-515). We might expect, then, that in the contrast situation prior experience with the sucrose stimuli to be used in a successive contrast paradigm might prolong the time period over which an interaction between the stimuli would be demonstrable.

The purpose of the present experiment was to examine the effects of prior experience with two sucrose solutions (32\% and $4 \%$ ) on the later occurrence of an interaction among these solutions when rats were shifted, after prolonged experience with $32 \%$ alone, to the $4 \%$ solution with either 1 or 10 days elapsing between shift stages.

\section{METHOD}

\section{Subjects}

The subjects were 42 naive male Sprague-Dawley rats purchased from Carworth Laboratories. All rats were caged individually and maintained on an 8-h dark/16-h light cycle. The rats were reduced to $80 \%$ of their free-feeding weight (mean $=306 \mathrm{~g}$ ) and maintained at that level for the duration of the experiment by once-a-day feeding. Water was constantly available in the home cage.

\section{Apparatus}

Prior experience with the sucrose solutions was given in a Plexiglas chamber, on one wall of which were two $1.5-\mathrm{cm}$-diam 
holes spaced $21.7 \mathrm{~cm}$ apart and $4 \mathrm{~cm}$ above the wire-mesh floor. Two graduated drinking cylinders, located outside the chamber, were programmed so that either could be moved into a drinking position in which the orifice of the drinking spout was centered in the $1.5-\mathrm{cm}$-diam hole, flush with the outside wall of the chamber. Pilot lights, mounted on either side of the chamber adjacent to the drinking access holes, were illuminated whenever the cylinder in closest proximity to that light was in the drinking position. A contact relay circuit was used to measure the licking response.

Single-stimulus training and retention testing were conducted in a similar test chamber located in a different room (see Flaherty et al., 1973, for further details).

\section{Procedure}

The experiment was divided into four phases: differential experience, preshift, retention interval, and postshift.

The purpose of the first phase of training was to give one group of animals experience with the two sucrose solutions to be used in the shift phases of the experiment. To this end, the animals were randomly divided into three groups $(n=14$ each) that differed in terms of which sucrose solutions they received in Phase 1 of the experiment; one group received both the $32 \%$ and $4 \%$ solutions, the second group received only $32 \%$ sucrose, and the third group received only $4 \%$ sucrose. The sucrose solutions were presented in the two-bottle apparatus (described above) in the following manner. When the rat was inserted into the chamber, the tube on the left side was in the drinking position and the tube on the right side of the apparatus was retracted. The rat was allowed 1-min access to the left tube beginning with its first lick; at the end of this time period, the left tube retracted and the right tube moved into the drinking position. The rat was then allowed access to this tube for $1 \mathrm{~min}$ beginning with its first lick. This procedure was continued for $6 \mathrm{~min}$, three 1-min access periods to each tube. One group (Group 32-4) received 32\% sucrose in one tube and $4 \%$ in the other tube (which tube contained which solution was randomized for each animal). A second group (Group 32-32) received $32 \%$ in both tubes, and the third (Group $4-4$ ) received $4 \%$ in both tubes. The dependent variables recorded during this phase (which was continued for 3 days) were the number of licks made to each tube and the latency to make the first lick when the tubes were switched.

The second phase of the experiment, preshift training, was conducted for 10 days. During this phase the rats were allowed 5-min access, beginning with the first lick, to the sucrose solutions in the single-bottle apparatus. Twenty-eight rats (the animals from the 32-32 and 32-4 groups of the differential conditioning phase) were given the $32 \%$ solution and the remaining 14 rats (the $4-4$ group) were maintained on the $4 \%$ solution.

In the postshift phase all animals were shifted to the $4 \%$ solution and tested for 4 days. For half the animals in each group postshift testing was initiated the day following the last preshift day. This condition was termed the 1 -day retention interval. Postshift testing did not begin for the remaining animals until 10 days following the last preshift training day (a 10-day retention interval). During the retention interval the rats were maintained at their $80 \%$ deprivation weights by once-a-day feeding and weighing.

\section{RESULTS}

\section{Prior Experience}

Data from the first phase of the experiment are presented in Figure 1. Each panel presents the lick rate for the three groups $(32-32,32-4,4-4)$ exposed to different sucrose concentration conditions. The data for the 1- and 10-day retention groups (a pseudovariable
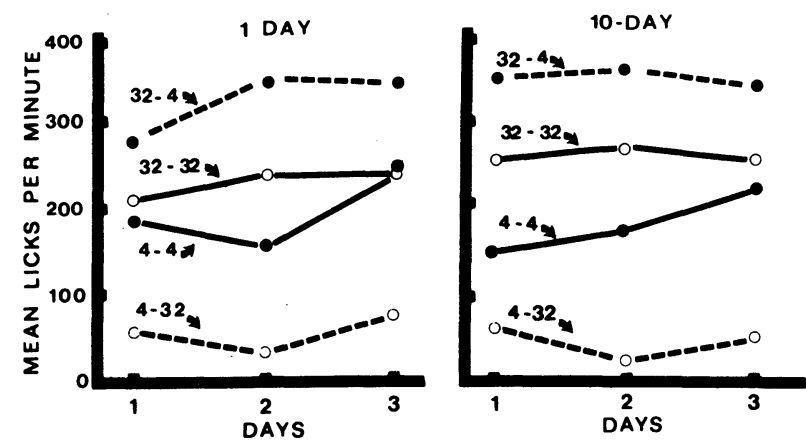

Figure 1. Mean lick rate as a function of sucrose concentration condition and training day. Curves labeled 32-32 and 4-4 represent animals that received the same concentration in both left and right tubes. The lick rates of the differential groups are shown separately for the $32 \%$ tube $(32-4)$ and the $4 \%$ tube (4-32).

at this point) are presented separately in the left and right halves of the figure. It is readily apparent that the group exposed to both solutions (Group 32-4) not only licked at a higher rate for the $32 \%$ than for $4 \%$ solution, but also licked at a higher rate for the $32 \%$ than did the group receiving only $32 \%$ (Group 32-32), and at a lower rate for the $4 \%$ solution than did the group receiving only $4 \%$. The reliability of these differences was confirmed by analyses of variance: The lick rate of Group $32-4$ for the $32 \%$ solution was reliably higher than the lick rate of Group 32-32 $[F(1,23)=$ $23.67, \mathrm{p}<.001]$, and this difference was not influenced by the retention interval pseudovariable $(F<1.00)$. Similarly, the lick rate of Group $32-4$ for the $4 \%$ solution was lower than the lick rate of Group $4-4[F(1,24)=$ $100.58, \mathrm{p}<.001]$, and this difference was not influenced by the retention interval pseudovariable $[F(1,24)=1.09, \mathrm{p}>.10]$. The small difference in lick rates between the $32-32$ and the $4-4$ groups was statistically reliable $[F(1,25)=7.70, \mathrm{p}<.01]$.

Thus, at the end of the first phase of the experiment, the lick rate of Group 324 to the two solutions was different enough to demonstrate both positive and negative contrast effects (cf. Flaherty \& Largen, 1975).

\section{Preshift}

The mean of the last 4 days preshift and daily postshift lick rates are presented in Figure 2. In the preshift period the animals receiving the $32 \%$ solution licked at higher rates than the $4 \%$ animals $[\mathrm{F}(2,36)=13.19$, $\mathrm{p}<.01]$ and, within the $32 \%$ condition, the rats that had received the prior $32-4$ treatment did not differ from the 32-32 rats (by Fisher's 1.s.d. test, $p=.05$ ). There was also no effect of the pseudovariable of retention interval $(F<1.00)$ nor an interaction between sucrose concentration and retention interval $(F<1.00)$.

\section{Postshift}

It is clear that, following the shift from $32 \%$ to $4 \%$, a large contrast effect was obtained in both groups when 


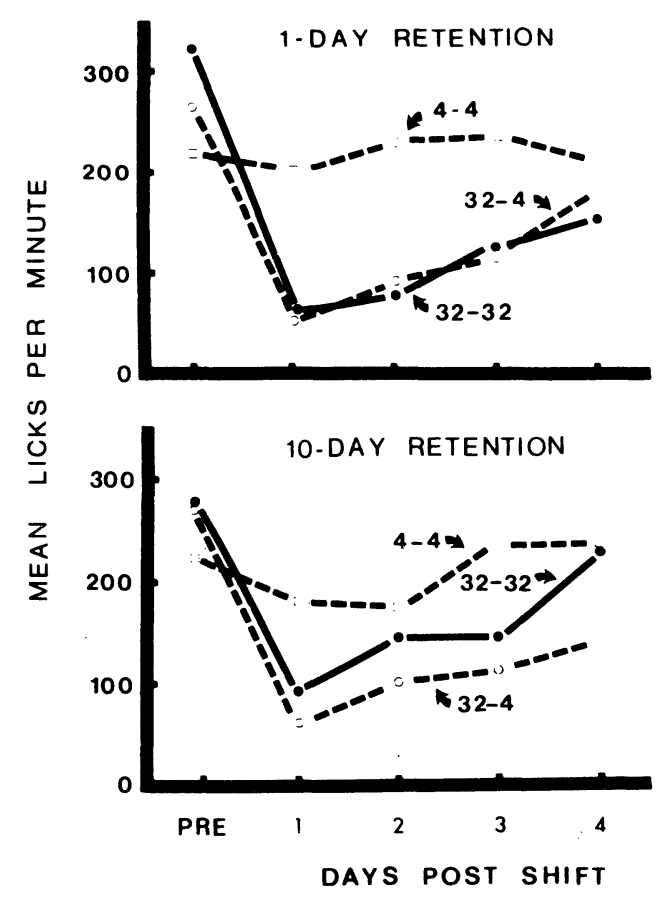

Figure 2. Terminal preshift and daily postshift lick rates as a function of sucrose shift condition, type of prior sucrose experience, and retention interval.

the shift was made following a 1 -day retention interval. That is, the animals shifted from $32 \%$ to $4 \%$ licked considerably less of the $4 \%$ than did animals always maintained on the $4 \%$ solution $[\mathrm{F}(2,17)=12.89$, $\mathrm{p}<.01]$. It is also clear that the size of the contrast effect was not influenced by prior differential experience (Group 32-32 equalled Group 32-4).

The results obtained following the 10-day retention interval, however, were somewhat different. A negative contrast was obtained in both shifted groups (Figure 2), but the contrast effect was larger in the group that had received prior differential experience. These latter results were supported by an analysis of variance, which indicated a reliable groups effect $[\mathrm{F}(2,18)=11.74$, $p<.01]$. Subsequent analysis with Fisher's 1.s.d. procedure $(p=.05$, two tailed) showed that both shifted groups licked at a lower rate than did the $4-4$ group; additionally, Group 324 licked at a lower rate than Group 32-32. The apparent tendency for faster recovery from the contrast effect in Group 32-32 relative to Group $32-4$ was not supported by the Groups by Days interaction term $[F(6,54)=1.87, p>.10]$.

The effects of prior differential experience on the retention of contrast following a 10-day retention interval are more clearly evident in Figure 3 . In this figure the data are plotted in terms of a contrast ratio (lick rate of the shifted group divided by lick rate of the unshifted group on the first postshift day). The retarding effect of prior differential conditioning on contrast loss over the retention interval is clear.

\section{DISCUSSION}

The principal finding of this experiment was that prior differential experience with the two sucrose solutions used in a successive contrast paradigm enhanced the contrast effect obtained following a 10-day retention interval. This prior experience had no effect on degree of contrast obtained after a 24-h interval between shift phases.

These data can perhaps be interpreted within the following framework. A given concentration of sucrose has both absolute and relative hedonic properties. The absolute properties may be related to some physiological correlate of concentration (Pfaffmann, 1960), whereas the relative hedonic properties are dependent upon a comparison between the focal solution and previously ingested solutions. Under some conditions, the relative hedonic properties seem to depend on immediate peripheral interactions among taste stimuli. For example, it has been found (Bartoshuk, 1968; McBurney, 1972) that sucrose concentrations lower than a preadapting concentration tend to taste bitter. However, the present experiment, and others cited earlier, make it clear that such interactions between sucrose solutions may take place readily with $24 \mathrm{~h}$ between successive access periods and, to a lesser extent, with as much as 10 days between access periods. Thus, a comparison must be made between currently experienced sucrose and the memory of previously experienced sucrose solution, and it is this comparison that influences responses to the focal stimuli (cf. Spear, 1967).

The effect of preexperience found in this experiment was apparently to enhance the relativistic response to sucrose over a long intershift interval. This effect may be related to Lawrence's work on transfer along a continuum. Lawrence (1949) found that prior differential experience with two stimuli lying far apart on a stimulus dimension enhanced the later learning of a discrimination between two closely related points on the same stimulus continuum. Perhaps the prior experience treatment administered in this experiment served to facilitate an otherwise difficult discrimination between the sweetness value of the postshift solution and the memory of the sweetness of the preshift solution.

Whatever the mechanism of operation of the prior experience variable, there remains the more basic problem of why the animal loses its tendency to respond on a relative basis with the passage of time. We do not have any data bearing directly on the mechanism of the apparent forgetting of the sweetness value of the preshift solution. If the gradual loss of contrast is due to interference, it is difficult to imagine what the interference might come from, since the rats encounter sucrose only in the experimental chambers. It is possible that either the

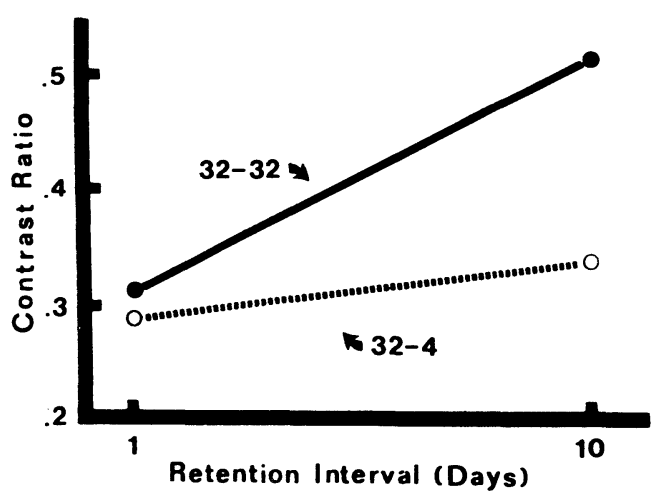

Figure 3. Ratio of lick rates of shifted to unshifted animals on first postshift day as a function of retention interval and prior sucrose experience. A ratio of 1.00 indicates no contrast effect. 
intake of water in the home cage or the postingestive consequences of carbohydrate intake provide a source of interference; however, we have no data on this matter.

It is also possible to interpret the loss of contrast in terms of simple decay of the memory trace (cf. Gleitman, 1971). However, if this was all that was involved, then one might expect that the 32-32 group from the differential phase would have had the stronger trace, because of more experience with the $32 \%$, and therefore would have shown the larger contrast effect after the retention interval. This, of course, was not the case.

\section{REFERENCES}

Bartoshux, L. M. Water taste in man. Perception \& Psychophysics, 1968, 3, 69-72.

Ciszewski, W. A., \& Flaherty, C. F. Failure of reinstatement treatments to influence retention in a negative contrast paradigm. The American Journal of Psychology, in press.

Flaherty, C. F., Capobianco, S., \& Hamilton, L. W. Effect of septal lesions on retention of negative contrast. Physiology and Behavior, 1973, 11, 625-631.

FlaherTy, C. F., \& LARgen, J. Within-subjects positive and negative contrast effects in rats. Journal of Comparative and Physiological Psychology, 1975, 88, 653-664.

Gibson, E. J. Perceptual learning. Annual Review of Psychology, 1963, 14, 29-56.

Gleitman, H. Forgetting of long-term memories in animals. In W. K. Honig \& P. H. R. James (Eds.), Animal memory. New York: Academic Press, 1971.

Gleitman, H., \& Steinman, F. Depression effect as a function of retention interval before and after shift in reward magnitude. Journal of Comparative and Physiological Psychology, 1964, 57, 158-160.
Gonzalez, R. C., Fernhoff, D., \& David, F. G. Contrast, resistance to extinction, and forgetting in rats. Journal of Comparative and Physiological Psychology, 1973, 84, 562-571.

Gordon, W. C., Flaherty, C. F., \& Riley, E. P. Negative contrast as a function of the interval between preshift and postshift training. Bulletin of the Psychonomic Society, 1973, 1, 25-27.

Hanson, H. M. Effects of discrimination training on stimulus generalization. Journal of Experimental Psychology, 1959, 58, 321-334.

JAMEs, W. The principles of psychology (Vol. I). Henry Holt, 1890. Dover edition, 1950.

LAWREnCE, D. H. Acquired distinctiveness of cues: I Transfer between discriminations on the basis of familiarity with the stimulus. Journal of Experimental Psychology, 1949, 39, 770-784.

MCBURNEY, D. H. Gustatory cross adaptation between sweet-tasting compounds. Perception \& Psychophysics, 1972, 11, 225-227.

Perkins, C. C., JR., \& Weyant, R. G. The interval between training and test trials as determiner of the slope of the generalization gradients. Journal of Comparative and Physiological Psychology, 1958, 51, 596-600.

Pfaffmann, C. The pleasure of sensation. Psychological Review, 1960, 67, 253-268.

SPEAR, N. E. Retention of reinforcer magnitude. Psychological Review, 1967, 74, 216-234.

Steinman, F. Retention of alley brightness in the rat. Journal of Comparative and Physiological Psychology, 1967, 64, 105-109.

(Received for publication December 23, 1976.) 